\title{
PRESENCIA DE HEINE EN LAS IMITACIONES ERUDITAS DEL CANTAR POPULAR
}

Numerosas referencias dieron cuenta del interés que suscitaba la poesía de Heine en nuestro país desde la década de los cuarenta del pasado siglo. Un artículo de Emilia Pardo Bazán publicado en el $n .^{\circ} 440$ de la Revista de España con el título «Fortuna española de Heine» revela la seducción que ejercía esta poesia sobre nuestros escritores, resumida en esta frase: "Tanto cautivó al público español la concentración de la poesía heineana... que se puso de moda imitar a Heine.»

Los ecos de la poesía germana habían llegado a otros poetas antes que a Augusto Ferrán y a Bécquer - Selgas, Arnao, Barrantes- pero, como señala José M." de Cossío, pronto viene a ser Heine el compendio y representación genuina de la poesía del sentimiento, que debe perder su denominación de alemana para tomar la más precisa de heineana ${ }^{1}$.

El papel que jugó la influencia germana en el lento proceso de renovación de la lírica que se produjo a lo largo de la segunda mitad del siglo XIX atañe a diversos géneros: la fábula, la balada, las rimas - entendiendo por tales las poesías becquerianas-y el cantar de origen erudito.

La crítica, generalmente, no ha destacado la presencia de Heine en las imitaciones del cantar popular, tal vez porque los poetas que las hicieron, salvo excepciones, compusieron otra clase de poesía por la que preferentemente se les conoce. Dejando a un lado a Ferrán, artífice de esta modalidad de cantares, conviene tener presente que los poetas más importantes

José M." de Cossio, Cincuenta años de poesia española (1850-1900), Espasa-Calpe, Madrid, 1960 , 1, pág. 400. 
de aquella época se relacionaron íntimamente con el cantar: Campoamor y Rosalía de Castro como creadores, Bécquer como teórico, aunque no falte quien le acredite también como cultivador del género ${ }^{2}$. Me referiré, sin embargo, preferentemente, a varios poetas menores dentro del muy numeroso grupo que perteneció al ámbito poético del becquerianismo, que hicieron a la vez rimas y cantares, trasladando los elementos y procedimientos heineanos al cantar y afianzando la escuela poética que iniciara Ferrán. Como la nómina es extensa citaré algunos nombres a título indicativo: Terencio Thos ${ }^{3}$, Isabel Villamartin ${ }^{4}$, Blanca de Gassós, Mariano Chacel ${ }^{6}$, Fernando Martínez Pedrosa ${ }^{7}$, Constantino Gil ${ }^{8}$, Ricardo Molly de Baños', Adolfo Llanos ${ }^{10}$, Luis Montoto ${ }^{11}$, Narciso Díaz de Escobar ${ }^{12}$ y En-

'En la colección de cantares anónimos y eruditos publicada por Melchor de Palau, Cantares populares y literarios, Montaner y Simón, Barcelona, 1900, figura Bécquer como el primero de los poetas de cantares; como ejemplo de cantar aduce Palau la conocida rima «Por una mirada, un mundo...». Conviene recordar que este breve poema bien pudo escribirse como cantar; apareció por primera vez en El Contemporáneo, en 1861, año en que se publicó la primera serie de cantares eruditos - La soledad, de Ferrán- y desde cuyas páginas Bécquer realizó la primera crítica de ellos. Se trata de una cuarteta octosilaba, estrofa propia del grupo genérico; además contiene otros rasgos comunes al cantar de origen culto, como enseguida veremos.

"Thos no publicó libro alguno de cantares, pero compuso muchos. El Semanario Popular publicó series de ellos en sus columnas. Palau le incluye en su colección antológica citada con una muestra de veinte.

4 Isabel Villamartín publicó Horas crepusculares, Madrid, 1865, que contiene muchos cantares junto a varias poesias becquerianas.

' Conozco de Gassó dos libros de cantares: Corona de la infancia. Lecturas poéticas y canciones para niños, Rivadeneyra, Madrid, 1868, y Cien cantares a los ojos, Vda. e Hijos de A. Galiano, Madrid, 1871 .

' De Mariano Chacel tengo noticia de un primer libro de cantares publicado en Valladolid, titulado Cantares de todos los colores, que no he visto. Conozco, en cambio Cantos de un gitano, Torriente y Cía., S. A. Madrid, 1878.

' En el libro Nubes y Flores, Tip. Minuesa, Madrid, 1878, Martinez Pedrosa incluye dos series de cantares junto a otras poesias. Conjuga elementos heineanos y campoamorinos con acierto. Prologa el libro Campoamor.

* Constantino Gil y Luengo publica en Madrid Cantos de un mudo, Imp. Pérez Dubrul, 1882

- Publica en Madrid y Barcelona, en 1875 Notas intimas, libro que contiene cantares junto a otras poesías. Palau recoge muestras suyas en la colección que he citado.

${ }_{10}$ Adolfo Llanos es un poeta estimable. Reúne en Hojas secas rimas y cantares sin discriminación, más próximos a Ferrán que a Bécquer. La edición que conozco se publicó en México, Imp. La Colonia Española, 1876.

"Este poeta sevillano sobradamente conocido insertó muchos cantares en sus libros. Destaco entre ellos: Melancolia. Cantares. Baldaraque, Sevilla, 1872; A la lumbre del Hogar. Poesías. Rasco, Sevilla, 1890; La musa popular. Cantares glosados, Rasco, Sevilla, 1893; y Paemas y Cantares, A. Saavedra, Sevilla, 1915.

12 Díaz de Escobar tiene más de una veintena de libros de cantares. Citaré algunos: Poesias y Cantares, con una nota biográfica de José Comas y un estudio crítico de Salvador Rueda, Imp. de J. Pons, S. A., Barcelona. Notas perdidas. Colección de cantares, Imp. El Correo de Andalucia, S. A., Málaga, 1881. Más cantares, 5." ed., Tip. Urbano, Málaga, 1890. Mencionaré otros más adelante. 
rique Paradas ${ }^{13}$.

La sensibilidad para la incorporación de lo germano existia antes de que se iniciara entre los poetas cultos la moda de imitar el cantar anónimo. Prueba de ello fue el intento de aclimatación de la balada, que no tuvo

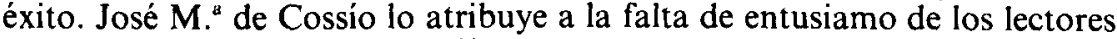
ante lo extraño de los asuntos ${ }^{14}$, mientras que Díez Taboada apunta acertadamente otra causa: el impulso hacia lo lírico se imponía despertándose el interés por el cantar ${ }^{15}$. Otros críticos - M. Cubero y J. Pedro Díazcorroboran el deslizamiento de la tendencia germanizante hacia la tendencia popular, argumentando que son precisamente los poetas que destacan como imitadores de Heine los que con más frecuencia realizan imitaciones del género popular ${ }^{16}$.

En la búsqueda de un nuevo camino para la lírica participan poetas de muy diversa adscripción poética, pero con el común denominador de la doble afición a lo popular y a Heine.

Factor decisivo en la formación de la nueva sensibilidad fueron las traducciones y versiones del poeta germano en nuestro país desde la década de los cincuenta. Mencionaré aquellas que considero decisivas con respecto al asunto que estoy tratando. Un año después del fallecimiento del poeta, ocurrido en París en 1856, aparece la traducción de Eulogio Florentino Sanz, de quince lieder de Heine en El Museo Universal ${ }^{17}$. La reseña del periódico deja constancia del éxito del poeta germano:

«Este poeta prusiano, el primero sin duda entre los líricos alemanes, se ha hecho popular en casi toda Europa, y sus poemas cortos, puestos en excelente música, se cantan en toda Alemania."

Florentino Sanz no se limitó a traducir. Verdadero poeta, recreó a Heine. En frase acertada de Cossío "creó un Heine en castellano", que tal vez no correspondia con toda fidelidad al modelo, pero fue este Heine y no el

13 Conozco tres: Undulaciones. Con un epilogo de Manuel Machado, El Secretariado, Madrid, 1893. Tristes y Alegres, La Catalana, Madrid, 1894, escrito en colaboración con Manuel Machado, e Impresiones. Cantares, Imp. Helénica, Madrid, 1913.

${ }_{14}$ Cossio, ob. cit., I, pág. 186.

is Juan M." Diez Taboada, "EI germanismo y la renovación de la lírica española en el siglo XIX», Filología Moderna, 5 (1961), págs. 21-25.

16 Véanse Manuela Cubero, Vida y obra de Augusto Ferrán, CSIC, 1965, págs. 193 y ss. Y Augusto Ferrán, Obras Completas, Ed. J. Pedro Díaz, Espasa-Calpe, Madrid, 1969, págs. 15 y ss.

${ }^{17}$ El Museo Universal, 1857, I, 9. Diez de estas canciones pertenecen al Intermezzo, dos a la Neuer Fruhling y una de cada uno de los libros Dieheimkehr. Neue Gedichte y Romancen. 
genuino quien suscitó la renovación lírica becqueriana proporcionando el molde rítmico que habría de servir de base a la rima ${ }^{18}$.

En El Museo Universal también, en 1861, ven la luz dieciséis composiciones traducidas en verso por Ferrán, con el título de Traducciones e imitaciones del poeta alemán Enrique Heine ${ }^{19}$. Ferrán pone el acento en los tonos populares contenidos en los poemas, de acuerdo con su gusto y sensibilidad, realizando, como Sanz, una recreación del poeta de los lieder. El mismo año publica $L a$ soledad ${ }^{0}$, serie de cantares originales, a imitación de los anónimos, pero fuertemente influidos por Heine, que inician la modalidad culta del género popular. Sendas reseñas del libro, de sobra conocidas, se hacen en El contemporáneo y en El Museo Universal a cargo de Bécquer y de Florencio Jáner respectivamente, y en ambas se menciona la filiación heineana de los cantares ${ }^{21}$. En el prólogo de la obra también lo reconoce el autor, al tiempo que explicita que la separación entre los cantares anónimos y los cantares imitados se deriva de esta filiación.

Otras traducciones y versiones se publican en aquellos años, y van afianzando el ambiente propicio para una más amplia recepción de lo heineano en los círculos literarios. Angel M. ${ }^{a}$ Dacarrete, creador de rimas y cantares, publica una muy temprana, anterior a la de Ferrán, en La América, el 8 de agosto de 1858 , acompañada de siete poemas, verdaderas rimas, y anteriores a la aparición de la primera rima de Bécquer. Julio Nombela publicó tres canciones del Intermezzo traducidas, en 1862, de nuevo en $E l$ Museo Universal $^{22}$; esta versión de Nombela es cercana a la de Ferrán; el traductor ha tomado como base métrica el octosílabo y la rima asonante propios del cantar popular. La Abeja, de Barcelona, revista que se publica desde 1862, y se subtitula «Revista científica y literaria ilustrada, principalmente extractada de los buenos escritores alemanes" fue uno de los mejores exponentes del influjo germano; el mismo año de su fundación aparece la traducción de dieciséis canciones de Heine y cinco de Uhland por Juan Font y Guitart ${ }^{23}$. Con el título de Recuerdos de Enrique Heine se publicaron en La Academia (1877, II, 235) otras poesías traducidas por Ferrán de las que se incluyeron en la edición de sus obras de La España Moderna, como remitidas desde Buenos Aires por Manuel Arguijo, amigo del poeta. No he destacado las versiones conocidas de J. A. Pérez Bonalde y de José Joaquín Herrero, considerado este como el más importante traductor de Heine, por

${ }^{18}$ Cossio, 1, pág. 362.

19 El Museo Universal, 1861, V, 46.

20 Augusto Ferrán, La soledad. Colección de cantares, Madrid, Fortanet, 1861.

${ }_{21}$ El Contemporáneo, 1861, I, 20. El Museo Universal, 1861, V, 46.

22 El Museo Universal, 1862, VI, 9.

2. La Abeja, 1862, I, 78. 
su menor relación con los cantares ${ }^{24}$. $\mathrm{Ni}$ otras menos conocidas, como las de Teodoro Llorente, publicadas en 1876 con el título Amorosas $^{25}$, y en 1885 con el de Poesias de Heine. Libro de los Cantares ${ }^{26}$.

El influjo de Heine informa dos corrientes que discurren en paralelo a lo largo del medio siglo: el cantar erudito y la rima. El débito al poeta germano y a Ferrán les otorga una poética muy próxima. Bécquer, ante los cantares de Ferrán indica que se trata de un nuevo género. Comentaristas del poeta de las rimas interpretan, no obstante, que el cantar imitado es un primer estadio del género, previo para el más logrado y verdadero nuevo género, la rima ${ }^{27}$. Desde este criterio se presenta al cantar erudito como el umbral de la rima, y Ferrán aparece como mero mediador estético entre Heine y Bécquer; implícitamente se relega el cantar imitado al papel de simple catalizador y transmisor de lo heineano, sin entidad ni autonomía como grupo poético. No lo creo asi: el cantar de procedencia culta constituyó una modalidad genérica con valor poético sustantivo en sí mismo, y con esta valoración pasó a la literatura como una de sus corrientes más significativas dentro de la lírica de la época. Ahora bien, si Ferrán intentó conseguir un nuevo tipo de canción, como manifiesta Bécquer, o el modelo surgió a partir de la mera imitación del lied desde la pauta estrófica del cantar anónimo, es asunto de escasa importancia. El resultado no fue la creación de un nuevo género -el cantar es bien antiguo--, sino de una modalidad de origen erudito, apéndice o rama del tronco popular, cuya poética viene delimitada por unos rasgos distintivos derivados de la fusión de elementos y procedimientos de la poesía germana y de nuestro género popular. La afinidad entre el lied y el cantar favoreció la inserción e integración de dichos elementos sin estridencias: en ambos casos se trata de una poesía imitada de la canción

${ }^{24}$ Con el título Poemas y fantasias publica la traducción del Intermezzo y otros poemas en la Biblioteca Clásica Navarro, con un prólogo de Menéndez y Pelayo recogido después en los Estudios de Critica Literaria. Rectifica en este prólogo un juicio negativo anterior sobre el poeta germano y reconoce que su «delicadeza incomparable se le escapó en otro tiempo».

${ }_{25}$ Amorosas. Poesias de los principales autores modernos, Valencia, Imp. Nicasio Ríus, 1873.

26 Poesia Arte y letras, 1885. Precede a los poemas una extensa introducción sobre el poeta de los lieder, con referencias a la influencia de éste sobre Bécquer, rebatiendo la tesis de Evaristo Correa Calderón que la negaba.

${ }^{27}$ Dice al respecto Gómez de las Cortinas: «Este nuevo género representado por Ferrán es el que había de alcanzar su culminación con las rimas de nuestro poeta (...) A partir de 1860, cuando ya la escuela heineana estaba definitivamente afianzada, Bécquer, en plena madurez abraza la poética de su amigo Ferrán, la nueva poesía que unificaba el cantar y el lied germano». "La formación literaria de Bécquer», Revista Bibliográfica y Documental, 1950, V, 1-4, 93. Para Díez Taboada la rima no es sino una estilización del cantar iniciada con el apartamiento del cantar que Ferrán realiza por influencia de Heine, y que culmina en la poesía de Bécquer; ello supone no sólo una renovación del género, sino el final de la tendencia renovadora en curso. "El germanismo y la renovación de la lírica espalola en el siglo XIX", Filologia Moderna, 5, 1961, 54-55. 
anónima, sencilla y sentimental, que expresa concisa y espontáneamente una idea, una reflexión; las diferencias no serán esenciales, sino de intensidad, de matiz, de tratamiento, de variación.

He citado antes el artículo de Pardo Bazán en el que la escritora gallega explica lo que Heine aporta a nuestra poesía; a su imaginación atribuye una más rica y adecuada expresión de los sentimientos «ensoñadora y dolorida», pero - añade - «no sólo por su intensidad, fuego y ternura nos sedujo Heine, sino también por su artística brevedad, por lo sabio de sus procedimientos, que contrastan con la verbosa abundancia de que suelen adolecer nuestros versificadores». En efecto, si en los lieder de Heine se armonizan elementos dispares, sentimiento, fantasía, reflexión, tristeza, ternura y sarcasmo, son, sin embargo características fundamentales la naturalidad expresiva y la concisión conceptual y formal. Los poemas, de escaso número de versos, apuntan una idea momentánea, fugaz, incluso al parecer insignificante, pero viva, vigorosa, arropada con la sencillez contraria a la afectación y retoricismo dominantes. En nuestro cantar popular - señalaba García Gutiérrez - «el pensamiento se distingue por su verdad y sencillez, la expresión por su propiedad y limpieza ${ }^{28}$. «La concisión, la agudeza, la sencillez, lo natural y espontáneo del estilo y la sobriedad - dice Ventura Ruiz Aguilera - son tan esenciales como el sentimiento y la idea ${ }^{29}$.

¿Qué elementos y procedimientos procedentes de Heine, convenientemente elaborados por traductores y poetas, se trasladaron al cantar imitado? Intentaré describir los más sobresalientes y justificarlos con algunos ejemplos.

\section{a) Pesimismo Inconcreto, Pesimismo Amoroso}

Procedente especialmente de los Lieder y del Intermezzo, el tono pesimista delata de inmediato la presencia de Heine. El excesivo sentimentalismo se percibe en la idea manifestada y en la abundancia abrumadora de términos como tristezas, fatigas, quejas, suspiros y lágrimas. Con frecuencia se trata de una poesía sentimentaloide, distante por completo de nuestra actual sensibilidad. Como explica Bousoño, la afectividad, para que sea poética, necesita de la plena aquiescencia del lector. Pero tal plenitud no la otorga sino cuando juzga, a la manera implícita propia de esta especie de

${ }^{28}$ Discursos leidos ante la Real Academia Española en la recepción pública del Excmo. Sr. Don Antonio García Gutiérrez, el 11 de mayo de 1862, Madrid, Rivadeneyra, 1982, págs. 32 y 33.

${ }^{29}$ Ecos Nacionales y Cantares, Madrid, Imp. de la Biblioteca de la Instrucción, s.a., págs. 273 y 274. 
juicios, como correcto y proporcionado el sentimiento al estímulo. Es decir, cuando el poeta llora demasiado ante las realidades poemáticas que el lector considera no merecedoras de tales excesos, se puede conseguir el efecto contrario en el lector: la displicente sonrisa. Se produce la inadecuación sentimental entre la causa y el efecto ${ }^{30}$.

Gamallo Fierros observa que el sello de Heine en Dacarrete es el lirismo intenso y la delicadeza, «el sentimiento que se deshace en lágrimas, la llorosa recriminación de amor» ${ }^{31}$. Bécquer dio cuenta del marcado pesimismo de los cantares de Ferrán en la crítica primera de $L a$ soledad ${ }^{32}$.

El pesimismo se manifiesta en el cantar imitado con matices derivados de la diversa sensibilidad poética de los creadores, pero generalmente con desmesura. Es común, en cambio, una doble temática, procedente de la causa de dicho pesimismo: la amargura inconcreta y las penas de amor. Ejemplos de uno y otro carácter aparecen en las series indiscriminadamente. El siguiente cantar de Luis Montoto puede considerarse representativo entre los de la primera clase:
A las sombras de la noche
les voy a contar mis penas.
Tan negros son mis pesares
como las sombras son negras ${ }^{33}$.

Los tipos más frecuentes dentro de los de pesimismo amoroso son los de queja y desengaño; tipos, como es sabido, importantísimos dentro de la canción amorosa de todos los tiempos. El ejemplo que transcribo a continuación es del poeta catalán Melchor de Palau:

\author{
iY eres tú la que te quejas \\ de que es amargo mi llanto! \\ iTú. que has vertido en mi pecho \\ la hiel de los desengaños! ${ }^{34}$.
}

30 Teoria de la expresión poética, Madrid, Gredos, 1976, 6." ed.,, II, p. 100.

3' Ángel M.“ Dacarrete, Estafeta Literaria, 25-VIII-1944, 11, pág. 21.

${ }^{32}$ Es conocidisima la frase de Bécquer: «Hay en ellos un grito para cada dolor, una sonrisa para cada esperanza, una lágrima para cada desengaño, un suspiro para cada recuerdo.n Artículo citado de El Contemporáneo.

"Melancolia. Cantares, Sevilla, Baldaraque, 1872, I, 21.

${ }^{34}$ Cantares populares y literarios, ob., cit., pág. 367. 
b) «DesmítificACIÓN» FEMENINA

Algunos comentaristas de Heine han intentado justificar con datos biográficos los motivos del pesimismo amoroso del poeta y el tratamiento escéptico que hace de la pasión amorosa. Tan sensible como Schiller -escribe Llorente- es víctima de las veleidades femeninas ${ }^{35}$.

Es probable que el fracaso amoroso de Heine proyectara en su obra la concepción "desmitificadora" de la mujer, cuyo tratamiento original, de indudable resonancia en la poesía becqueriana, repercutió en el cantar imitado. La mujer se presenta como una muchacha cualquiera, capaz de engaños e infidelidades, e incluso perversa. Heine expresa la traición y perversidad femeninas mediante un pensamiento poético, metafórico, pero en la sencillez de su concepción espontánea.

Heine eligió el motivo de las serpientes como término comparativo de la perfidia femenina. Este motivo atrajo a Bécquer, dando origen, como es bien sabido, a una de sus más conocidas rimas; inspiró, asimismo, un poema de Dacarrete y un cantar de Ferrán ${ }^{36}$. Pero también Campoamor, Paradas y Juan Ramón Jiménez escriben cantares cuyo núcleo temático gira en torno de la infidelidad y la perfidia femeninas. Casi adolescente, compone el poeta de Moguer los siguientes cantares, bajo la influencia inmediata de Ferrán o de Bécquer, y más lejana de Heine:

Mirad qué arrogante pasa:

¿Cuánto esplendor en el cuerpo!

¿Cuánta miseria en el alma!

¿Creerás que me importan

tus fieros desdenes?

Busca bien en tu oscura conciencia,

¿Verás como pierdes! $!^{37}$. XXXI.

${ }^{35}$ Poesias de Heine. Libro de los Cantares, Prólogo de Teodoro Llorente, págs. XXX y

36 Véase al respecto el artículo citado de Gamallo fierros en Estafeta Literaria. El de Rafael Balbin, "Sobre la influencia de Augusto Ferrán en la rima XLVII de Bécquer", Revista de Filologia Española, Madrid, XXVI (1942) 319-34, y «Poesía Becqueriana», VIII, Cincuenta años..., ob. cit., págs. 346 y ss.

"El Programa, n. ${ }^{\circ}$ 18, Sevilla, 1-VI-1899. 


\section{c) Subjetivismo e InTIMismo}

Teniendo en cuenta que la expresión del sentimiento es la muestra más evidente de la subjetividad, el sentimiento extremo conducirá a un extremado subjetivismo.

Los comentaristas de Bécquer achacan el agudo subjetivismo del poeta al influjo de Heine. Hay que reconocer que tanto en las versiones de este que hiciera Florentino Sanz, como en las que realizara Ferrán, se respeta el tono eminentemente subjetivo de los lieder y poemas de aquel. Por ejemplo, en los que comienzan "Yo tus ojos he besado..." y "Yo te amé cuando niño..." Ferrán ha colocado un significativo yo enfático inicial ${ }^{38}$. Bécquer recibió esta influencia de Heine a través de Ferrán - como Balbín creeo bien de las versiones de Florentino Sanz; en todo caso se advierte que el subjetivismo se va orientando hacia la interiorización. Profundizando en este hecho J. Frutos y Gómez de las Cortinas señalan que en este rasgo radica una de las aportaciones más importantes de Heine a la lírica de su tiempo, esto es, el análisis del yo íntimo ${ }^{39}$.

El intimismo se presenta en el cantar erudito con variantes temáticas que requeririan un análisis puntual que aquí no procede: la amargura interior inconcreta, el deseo vago innominado, la incapacidad para eludir el propio sufrimiento, la percepción de la propia soledad, la inminencia y el deseo de la muerte. El sueño como motivo identificador de la muerte aparece frecuentemente. Conviene recordar al respecto la traducción de un poema de Heine, realizada por Ferrán, que apareció en El Eco del Pais, el 27 de marzo de 1865:

La vida es la negra noche. la muerte un sueño pesado.

Ya anochece... tengo sueño. ¿Ha sido el dia tan largo. ${ }^{40}$.

Llamo la atención sobre la elaboración que hicieron Ferrán y Terencio

${ }^{3 R}$ Véase A. Ferrán, Obras Completas, ed. J. Pedro Díaz, págs. 119-122.

"Dice textualmente: «... el idealismo difuso, el análisis del yo intimo, la vaguedad, la melancolia, la naturaleza considerada como espejo de lo invisible, el tono menor y la novedad métrica son los principales caracteres que sus obras ofrecian a la poesía contemporánea (...) los nuevos poetas buscan en el yo íntimo, en los sentimientos indefinibles, en los vagos anhelos que se agitan temblolrosos en los oscuros penetrales del alma y adquieren una expresión de matiz musical». En «La formación literaria de Bécquer», pág. 94.

${ }^{40}$ Es traducción del poema 87 de Die Heimkehr. 
Thos de temas y motivos en sendos cantares a partir del conocido poema de Heine, traducido por Ferrán, «Niña, sobre mi pecho pon tu mano...». El débito de ambos con el poema heineano ha sido suficientemente destacado por la $\mathrm{crí}^{\prime} \mathrm{ca}^{41}$, pero merece la pena precisar algunos aspectos. Transcribo a continuación ambos poemas:

La noche oscura ya llega, todo en el sueño descansa y tan sólo el corazón dentro del pecho trabaja ${ }^{42}$. A. FERRÁN.

Aqui dentro de mi pecho tengo una fragua metida. ¿Cuándo dormirá el herrero

que trabaja noche y dia? ${ }^{43}$.

T. THOS.

El poema de Heine tiene como tema la ineluctable y deseada llegada de la muerte. Thos, como Heine, se sitúa desde una perspectiva subjetiva, mientras que Ferrán lo hace desde el objetivismo de la reflexión general. Con procedimientos que of recen alguna variación, los motivos -el corazón que trabaja, la muerte/sueño/descanso- se repiten en los tres poemas. El fenómeno de rehacer los cantares, variando determinados temas, motivos y procedimientos, está generalizado en esta modalidad, y viene dado por la misma génesis y naturaleza del grupo poético, que nace como imitación.

El subjetivismo es evidente en el ejemplo siguiente, procedente del libro Hojas secas, de Adolfo Llanos. Los motivos que aparecían en los ejemplos anteriores remiten a otros significados, mediante distintos procedimientos:

Corazón ¿por qué despiertas

¿' El original de Heine es «Lieb, Liebchen, Leg's Handchen aufs Herze mein...». Lieder IV, Junge Leiden, como señala M. Cubero. La traducción es la siguiente: Niña, sobre mi pecho pon tu mano.../ iQué golpes! ¡Que inquietud!.../ Es que trabaja dentro un carpintero/ clavando lentamente mi ataúd./ Día y noche trabaja/, trabaja sin cesar...;/ date prisa, maestro,/ que tengo sueño y quiero descansar./ Fue publicada en La Ilustración Española y Americana el 24 de enero de 1873.

42 La soledad en La pereza, CXIX, pág. 82.

${ }^{43}$ Palau, Cantares populares y literarios, pág. 310. 
al ver tu dicha perdida?

Duerme, que el sueño es la vida

de las esperanzas muertas ${ }^{44}$.

d) RECATO EN LA EXTERIORIZACIÓN SENTIMENTAL

J. Pedro Díaz observó acertadamente al analizar los cantares de Ferrán "cierto tono de recato en la manifestación del sentimiento", que se percibe en la desviación del poema hacia la reflexión objetiva para evitar la efusión lírica.

Este pudor o recato constituye una actitud adelantada, moderna, originada precisamente como reacción en contra de los excesos sentimentales del romanticismo. En el subjetivismo contemporáneo, más agudo que el de la etapa anterior, entra un ingrediente configurativo que antes no existía, que Bousoño ha puesto de relieve: un extremo pudor, nacido por una parte como protesta contra la orientación sentimental romántica, y por otra como fruto de la tendencia a sugerir, resultado a su vez del especial subjetivismo de la época; pudor que prohíbe el exhibicionismo de la intimidad ${ }^{45}$.

Cuando los imitadores de cantares intentan recatar el propio sentimiento, lo hacen, a imitación de Ferrán, orientando el poema hacia la reflexión moral, didáctica, admonitoria o gnómica. En este caso el cantar imitado se aproxima al cantar anónimo, que, como es sabido, tiene en la veta sentenciosa una de las corrientes tradicionales más vigorosas. Hay ocasiones en las que la contención lírica se resuelve mediante una orientación irónica.

En el ejemplo siguiente de Ferrán el tono admonitorio de la reflexión evita la implicación subjetivista:

Si os encontrais algún día dentro de la soledad no pidais consuelo al mundo porque él no os lo puede dar ${ }^{46}$.

El lector percibe en ocasiones que la reflexión objetiva implicita el propio sentimiento del poeta, como ocurre con esta soledad de Díaz de Escobar:

\footnotetext{
4 Hojas secas, ob. cit., pág. 75.

${ }^{45}$ Bousoño, II, pág. 205.

th La soledad, XXXVI, pág. 48.
} 


\title{
¿Qué fatigas sufre el alma que llama a una sola puerta y siempre la ve cerrada! ${ }^{\mu 7}$.
}

Así sucede con la siguiente seguidilla gitana de Manuel Machado:

\author{
Las que se publican \\ no son grandes penas, \\ ...las que se callan y se llevan dentro \\ son las verdaderas ${ }^{48}$.
}

\section{e) LA SUGERENCIA}

La tendencia a la concisión y la brevedad del poema propician la sugerencia, porque citando a Bousoño «QQué es sugerir sino decir poco para que el oyente entienda mucho?». Los poetas, desde Verlaine y antes - añade el crítico - han intentado, en esa vía "torcerle el cuello a la elocuencia» mediante el arte de la insinuación ${ }^{49}$.

El esquematismo de la expresión implica una densidad y plenitud significativas. Es el lector quien completará lo sugerido y no explicitado, y por este motivo la significación no puede tener contornos definidos y precisos, sino todo lo contrario. De ahí que la vaguedad acompañe a la sugerencia. Esta es, asimismo, un modo de manifestarse el individualismo, y por ello posee un carácter subjetivo.

Bousoño distingue una sugerencia lógica y una sugerencia irracional, y señala en esta distinción el cambio del procedimiento desde la poesía romántica a la poesía contemporánea.

La sugerencia que como procedimiento observamos en el cantar erudito no debe atribuirse únicamente a la influencia heineana, porque la denominada intención en el cantar popular no es más que una clase de sugerencia. Sin duda la influencia de Heine reforzó este procedimiento intrínseco al cantar imitado, pero de ningún modo deberá considerarse como una aportación exclusiva del poeta de los lieder, que gusta sobre manera de este

47 Más coplas, Málaga, Tip. Zambrana, Hnos., 1901, «Victorianas», pág. 53.

4 Tristes y alegres. En colaboración con Enrique Paradas. Madrid, La Catalana, 1894, s.p.

49 Bousoño, II, pág. 426. 
procedimiento. Conviene recordar sobre este punto que Bécquer atribuye a los cantares de Ferrán «la misma intención que los del pueblo».

Florentino Sanz traslada a sus versiones la sugerencia heineana con acierto. Ejemplos notables son los lieder 49 y 51 del Intermezzo, muy conocidos: "Al separarse dos que se han querido..." y «Por qué, dime, bien mío, las rosas...".

Entre los imitadores es Campoamor uno de los que utilizan reiteradamente este procedimiento, aunque siempre dentro de su personalísimo estilo. Díez Taboada mencionó la sugerencia campoamorina como rasgo que le acerca a Heine, si bien puntualiza diferencias de matiz en ambos poetas y no se refiere en concreto a los cantares ${ }^{50}$. No olvidemos que el mismo poeta señalaba ese rasgo como esencial en sus humoradas. Dentro de la serie que titula Epigramáticos escogemos dos ejemplos:

De noche, solo y a pie, voy a tu lado y me acuesto, me vuelvo, nadie me ve... Todo en sueños, por supuesto ${ }^{51}$.

Cuando pasas por mi lado sin tenderme una mirada, ¿no te acuerdas de mi nada o te acuerdas demasiado $?^{52}$.

Manuel del Palacio y Enrique Paradas utilizaron el procedimiento de la sugerencia en buen número de cantares; aquel en la línea satírica que caracterizó su poesía. Paradas, poeta de producción muy desigual desde el punto de vista artístico, fue un maestro en el arte de decir mucho con pocas palabras. Sus más acertados cantares son reflexiones sintéticas, próximas al aforismo. Suya es esta soledad procedente del libro Undulaciones, cuyo contenido mismo define el suspiro como máximo procedimiento de sugerencia:

so Dice Diez Taboada: «En la actitud de tomar del exterior sólo el rasgo que interesa están próximos los dos modos de Heine y Campoamor, así como en el lenguaje espontáneo, en la brevedad de los poemas y en el sugerir algo que el poema en sí no dice (...) lo sugerido en Campoamor suele ser una idea que sirva de enseñanza para la vida o un picaresco excepticismo; en Heine, la evocación de un sentimiento teñido a veces de sarcasmo». "El germanismo...», pág. 27.

\$1 Doloras y Cantares, 9. aumentada, Madrid, Alfonso Durán, 1866, 5." Parte, Epigramáticos, pág. 380.

"Ibidem, pág. 375 . 
Dijo a la lengua el suspiro:

échate a buscar palabras

que digan lo que yo digo ${ }^{53}$.

De otro libro de Paradas Impresiones. Cantares, procede el cantar siguiente:

El tiempo es un buen amigo

que sin haberle hecho daño

la va tomando contigo ${ }^{54}$.

\section{f) LA INTERrogación Retórica y el APóstrofe}

En la versión de Florentino Sanz las cuatro estrofas del poema «Warum sind denn die Rosen so blass... " están constituidas por una serie de interrogaciones retóricas dirigidas a la amada, a la que se pregunta con «ilo sabes?», y se invita a responder con el imperativo retórico "díme»:

¿Por qué, dime, bien mio, las rosas tan pálidas yacen?...

En el poema "Vergilted sind meine Lieder» la interrogación retórica se sitúa intercalada en el segundo verso de cada estrofa y ambas llevan apóstrofe e idéntica estructura:

53 Undulaciones, Madrid, El Secretariado, 1893, pág. 156. Paradas mantuvo una estrecha relación amistosa con los hermanos Machado. Su influencia en los cantares de ambos es evidente y no ha sido estudiada con detenimiento. En colaboración con Manuel publicó Tristes y alegres al año siguiente de publicarse Undulaciones; este libro lleva un elogioso epílogo de Manuel. La amistad con los hermanos se pone de manifiesto en Impresiones. Cantares, libro posterior de Paradas que antes he citado; dedica la serie Soleares a Manuel con estas palabras: "A quien mejor las escribe: a mi amigo Manuel Machado". Y la serie Malagueñas a Antonio, en estos términos: "Al gran poeta, mi excelente amigo Antonio Machado". He estudiado los cantares de Paradas en un amplio apartado de La poesia de cantares en la segunda mitad del siglo XIX, Madrid, Universidad Complutense, 1988, págs. 445-458.

${ }^{54}$ Impresiones. Cantares, pág. 111. 
¿Qué están empozoñadas mis canciones...!

¿Y no han de estarlo, di... ?

En otras ocasiones la interrogación aparece como verso final de la cuarteta octosilaba, repitiéndose a modo de estribillo en todas las estrofas que componen el poema; Véase la siguiente traducción del poema $64 \mathrm{de} E l R e$ greso:

Tienes diamantes y perlas

y cuanto hay que apetecer,

y los más hermosos ojos

¿Qué más anhelas, mi bien?"s5

Este procedimiento expresivo fue trasladado al cantar erudito por aquellos poetas que participaron más directamente del ambiente poético que se formó en torno a Bécquer. Los ejemplos son muy numerosos y el resultado artístico variable. De Blanca de Gassó es la seguidilla siguiente:

Tus ojos fueron cuna

de mi esperanza.

iAy! ¿Por qué la mecieron

para matarla?

El apóstrofe, en cambio, es un procedimiento habitual tanto en el cantar popular como en el lied; no es innovación heineana que penetre en el cantar imitado, aunque esta influencia intensificara su uso con las fórmulas del imperativo retórico procedentes de las traducciones de Sanz.

El término niña del apóstrofe que aparece en las traducciones de Heine se utiliza indistintamente en los cantares anónimos y eruditos. En las imitaciones de carácter más popular, niña se sustituye intencionadamente por serrana, morena o compañera, de uso más frecuente en el cantar anónimo. Así lo hacen poetas eximios, como Manuel Machado, Salvador Rueda y Juan Ramón, y otros muchos poetas secundarios, como Díaz de Escobar y Paradas. He aquí una seguidilla gitana representativa, original de M. Machado:

ss Veánse las traducciones citadas de Florentino Sanz.

${ }^{5 n}$ Cien cantares a los ojos, 46, pág. 22. 
Desde que te fuiste, serrana, y no vuelves, ino sé qué dolores son estos que tengo, ni dónde me duelen! ${ }^{57}$

El uso simultáneo de ambos procedimientos en el mismo cantar es frecuentísimo, y aparece en las traducciones de Heine, como se ha visto en las que he reseñado anteriormente. El ejemplo siguiente es significativo; se trata de una seguidilla con estribillo, original del poeta Mariano Chacel:

\author{
Qué me dicen tus ojos \\ cuando me miran? \\ ¿Me hablan de amor acaso? \\ Dime, alma mia, \\ ¿o sólo en ellos \\ quieres con tu mirada \\ mostrarme el cielo? ${ }^{58}$
}

\title{
g) Biestrofismo Y POLIESTROFISMO
}

Los imitadores de cantares siguen fielmente, salvo contadas excepciones, las formas estróficas del cantar anónimo. Fijan su predilección por la cuarteta octosílaba; cuando los tonos heineanos disminuyen en las dos décadas finales del siglo, coincidiendo con el auge del folklore, van utilizando cada vez más frecuentemente las estrofas más netamente populares, soledad y seguidilla gitana, en la medida en que se siente émulos del poeta-pueblo. En el segundo libro de cantares, La pereza, Ferrán los compone con dos o más estrofas. Este procedmiento se ha atribuido a la influencia de Heine. Díez Taboada considera que este uso acentúa la estrecha relación de sus cantares con los lieder que tradujo, y recuerda al caso la cita de Henri Blaze sobre el lied:

37 Tristes y Alegres, Seguidillas, s. p.

${ }^{38}$ Cantos del gitano, pág. 8. 
«Le veritable lied, le lied-chanson, n'a d'ordinaire qu'une strophe, deux au plus, qui se répondent l'une à l'autre, ainsi que la voix et l'écho" ${ }^{59}$

Parece, no obstante, que Ferrán quisiera justificar implícitamente el origen popular del procedimiento métrico empleado, al incluir en la serie de cantares anónimos que precede a la suya de La soledad varios cantares anónimos biestróficos y poliestróficos: dos biestróficos, uno de tres estrofas, uno de cuatro y otro de cinco ${ }^{60}$. Y en La pereza, en nota a pie de página, transcribe cantares populares biestróficos. Lo que parece incuestionable es que en los cantares poliestróficos se encuentran las mejores muestras de lirismo subjetivo.

El encadenamiento estrófico asemeja el cantar a la rima, y, por lo tanto, a muchos de los poemas de Heine traducidos, especialmente cuando se trata de seguidillas o de seguidillas gitanas, cuya desigual medida versal propicia un ritmo más suave y un lirismo más profundo como ha observado J. Pedro Díaz refiriéndose a ciertos cantares de Ferrán ${ }^{61}$. A ello sin duda contribuye el que la estrofa sea utilizada con un espíritu poco acorde con lo popular original. Hay que reconocer la maestría de Ferrán en el uso del procedimiento, encadenando las estrofas en torno a un núcleo temático, a veces leve y difuso, otras mediante un indicio argumental, como en las rimas. Verdaderos aciertos son los cantares XXXIV — «El dulce sonido / de tu voz alegre / cuando te callas se aleja despacio / hasta que se pierde / ..." y CXLI - «De caminar ya rendido / me senté al caer la tarde / a la orilla del camino / ...- compuestos de tres y seis estrofas, seguidillas gitanas y soledades respectivamente, como se advierte en las primeras estrofas ${ }^{62}$.

Luis Montoto construye cantares poliestróficos glosando cantares anónimos $\mathrm{u}$ originales de sus poetas predilectos, que coloca al frente de los suyos. Se trata de un procedimiento de intertextualidad: los versos del cantar glosado van siendo colocados como verso final de cada una de las estrofas del cantar de Montoto. El que tomo como ejemplo es un cantar en soledades, glosa de una conocida soledad de Ferrán:

${ }^{59}$ Henri Blaze, Ecrivains et poèts de lÁllemagne, Paris, 1846, págs.3-5. Tomo la cita de «El germanismo... ", pág. 51.

to La soledad. Cantares del pueblo, LXXX, LXXXI, LXXXII, LXXXIII y LXXXIV. Hay abundantes ejemplos de cantares poliestróficos en las colecciones anónimas. En los de «valentia» - valentones para Lafuente Alcántara, bravucones para Rodríguez Marín - se entabla un diálogo en el que un cantar exige como respuesta otro. Ferrán compone soledades encadenadas dispuestas para el diálogo cantador-cantadora en La pereza, CXXIV.

o1 Augusto Ferrán, Obras completas, Introducción de J. Pedro Díaz, pág. XLIV.

${ }^{62}$ La pereza, XXXIV, pág. 92 y CXLI, pág. 114. 
Voy como si fuera preso, detrás camina mi sombra, delante mi pensamiento. Augusto Ferrán.

Entre nieblas y reflejos, por la senda de la vida voy como si fuera preso.

Senda estrecha y escabrosa; atrás no vuelvo la vista, atrás camina mi sombra.

Puesta la vista en el cielo, van, heraldos de mis ansias, delante mis pensamientos ${ }^{63}$.

Díaz de Escobar gusta del poliestrofismo especialmente en la serie de cantares que denomina trinitarias Es arriesgado considerar algunas de las cuarenta y siete composiciones que integran la serie que he manejado como cantares en sentido estricto; el poeta las incluye en libros totalmente de este carácter, como en Percheleras y Trinitarias ${ }^{64}$, y en Más coplas ${ }^{65}$. El débito lejano a Heine y el más próximo a Rosalía de Castro es indudable. El siguiente cantar biestrófico es paradigmático dentro de estos cánones:

\author{
¡No he visto invierno más triste! \\ iSin sol que preste espezanzas! \\ ¡Siempre lluvias en el valle! \\ ¡Siempre nieve en la montaña! \\ ¿Invierno que yo reflejo! \\ ¡En mis ojos siempre lágrimas! \\ ¡Siempre sombras en la mente! \\ iSiempre dudas en el alma. ${ }^{\text {po }}$
}

${ }^{63}$ La musa popular. 111 págs. 11 y 12.

${ }^{4}$ Percheleras y Trinitarias (Colección de Cantares), Madrid, Imp. El Renacimiento, 1892.

os Más coplas (Percheleras, Trinitarias, Victorianas, Capuchineras). Con un prólogo del Excmo. Sr. Don José Canalejas y un soneto final de Don Salvador Rueda, Málaga, Tip. Zambrana, Hnos., 1901.

${ }^{6}$ Percheleras y Trinitarias, Trinitarias, VII, pág. 78. 
Salvador Rueda compone cantares poliestróficos dentro de la modalidad que denomina poema en cantares. No se trata, sin embargo, de una innovación; una vez más estamos ante el procedimiento que venimos señalando: construir un cantar encadenando las estrofas en torno a una unidad temática: la guitarra, la mariposa, los labios femeninos, o el mismo cantar, que tal es el caso del que comienza: «Para que tú lo comprendas / te hago un poema en cantares / y sólo quiero por gloria/ la gloria de que los cantes/ ... ${ }^{67}$.

Paulatinamente la presencia de Heine en el cantar imitado irá disminuyendo; fenómeno inverso al proceso de intensificación de los elementos más netamente populares propiciado por el auge del folklore que tiene lugar en las postrimerias del siglo. Pero no desaparece; difuminada por las sucesivas elaboraciones se hará irreconocible en la lírica del siglo XX.

"7 El pais del sol. Madrid, Valero Díaz, s. a., pág. 211. 